\title{
LA IMPORTANCIA DE LLAMARSE JUEZ \\ CONSTITUCIONAL: RECONOCIENDO LOS \\ DERECHOS DE LAS FAMILIAS LGBTI VÍA JUDICIAL'
}

\section{The Importance of Being Constitutional Judge, Recognizing the Rights of LGBTI Families}

\author{
ROCÍO DEL PILAR PEÑA HUERTAS 2 \\ Universidad del Rosario, Bogotá \\ rocio.pena@urosario.edu.co \\ MARÍA MÓNICA PARADA HERNÁNDEZ3
Universidad del Rosario, Bogotá
paradah.maria@urosario.edu.co
}

Cómo citar/Citation

Peña Huertas, R. P. y Parada Hernández, M. M. (2016).

La importancia de llamarse juez constitucional:

reconociendo los derechos de las familias LGTBI vía judicial.

Anuario Iberoamericano de Justicia Constitucional, 20, 315-333

doi: http://dx.doi.org/10.18042/cepc/aijc.20.11

\section{Resumen}

Este artículo aborda la inclusión de los derechos de la comunidad LGBTI en la democracia colombiana y el papel de los jueces en dicha inclusión. El interrogante planteado es si los jueces en sus sentencias crean o aplican reglas que reconocen derechos que el legislador no ha desarrollado por vía de leyes, aun cuando pueden encontrarse en la Carta Política. Para analizar el problema, se da cuenta de las reglas

1 La presente investigación fue financiada por el Fondo de Investigación de la Universidad del Rosario, FIUR.

2 Doctora en derecho, profesora de carrera académica de la Facultad de Jurisprudencia de la Universidad del Rosario, Colombia, y Editora de Estudios Socio-Jurídicos.

3 Abogada, socióloga y estudiante de Maestría en Derecho de la Universidad del Rosario. 
creadas y aplicadas por algunos jueces en las sentencias sobre litigios de los derechos que tienen o no los ciudadanos que pertenecen a la población LGBTI (lesbianas, gays, bisexuales, transgénero e intersexuales), específicamente los que surgen cuando deciden conformar una familia voluntariamente.

\section{Palabras clave} va; jueces.

Derechos; inclusión democrática; familias homoparentales; legislación inclusi-

\section{Abstract}

This article discusses the inclusion of the rights of the LGBTI community in Colombian democracy and the role of the judges in such inclusion. The question we ask is whether the judges in their rulings create or apply rules that recognize rights that the lawmakers have not developed through the enactment of laws, even though such rights may be found in the Constitution. To analyze the problem, we review the rules created and applied by judges in decisions involving litigation over the rights of citizens who belong to the LGBTI (lesbian, gay, bi-sexual, trans-gender and inter-sex) community, specifically when they voluntarily decide to establish a family.

\section{Keywords} judges.

Rights; democratic inclusion; same-sex parent families; inclusive legislation; 


\section{SUMARIO}

I. INTRODUCCIÓN. II. LA DEMOCRACIA, CATÁLOGO DE REGLAS MÍNIMAS. III. EL JUEZ CONSTITUCIONAL EN LAS DEMOCRACIAS, DEBATE VIEJO, ELEMENTOS NUEVOS. IV. LOS DERECHOS DE LAS MINORÍAS POLÍTICAS EN COLOMBIA: UN CATÁLOGO EN CONSTRUCCIÓN. V. DESARROLLO DE LA JURISPRUDENCIA CONSTITUCIONAL DE DEFINICIÓN DE FAMILIA. VI. DOS EJEMPLOS DE INCLUSIÓN JUDICIAL Y DERECHOS DE FAMILIA HOMOPARENTAL. VII. ALGUNAS CONJETURAS A MANERA DE CONCLUSIONES. VIII. BIBLIOGRAFÍA.

\section{INTRODUCCIÓN}

Hace más de cincuenta años el Congreso de los Estados Unidos aprobó The act of civil rights, en el que se prohíbe la discriminación ante la ley en razón del color de los ciudadanos. Este hecho, aunque importante, fue uno más en el camino del respeto a la diferencia en este país, y no hubiera sido posible sin la valerosa sentencia de la Suprema Corte en 1954 que falló a favor de Linda Brown, hito que inició el fin de la segregación racial por vía legal en los Estados Unidos. Este es solo uno de los ejemplos del papel de los jueces en la inclusión de los derechos de las minorías en el catálogo de derechos democráticos.

No obstante, el papel que tienen los jueces en la inclusión de los derechos por vía judicial, particularmente de las minorías políticas, es un tema problemático: por un lado, revela la importancia del juez en un Estado democrático por cuanto reconoce los derechos a quienes son jurídicamente invisibles; pero por otro, muestra al Estado como incapaz de tramitar en el parlamento temas propios de las políticas públicas. El problema que se plantea es si les es dado a los jueces, mediante sentencias, crear o aplicar reglas que reconozcan los derechos de algunas minorías que, aunque el legislador no haya desarrollado por vía de leyes, se encuentren en el catálogo de derechos para los miembros de las mayorías. 
La población LGTBI, en términos de representación política, es una minoría que busca que se le reconozcan sus derechos plenamente dentro de la sociedad en la que viven; en este sentido entender cómo afecta esto social y jurídicamente a las grupos sociales, es fundamental para el logro y garantía de estos reconocimientos. Sobre matrimonio del mismo sexo encontramos trabajos como los de Lee y Hicks (2011), que explican el papel de los medios en la afectación de las actitudes frente a esto, o sobre la actitud de la población heterosexual frente al mismo fenómeno (Moskowitz et al., 2010); esta última investigación contribuye a la discusión y el conocimiento sobre los derechos implicados en la conformación de la familia de las personas que pertenecen a la comunidad LGTBI.

El artículo se divide en cuatro secciones. La primera presenta algunas definiciones de democracia, útiles para contextualizar el tema y el debate actual sobre el papel de los jueces. En la segunda se ilustra la experiencia de los derechos de las familias homoparentales en Colombia a través de un recuento de los aportes judiciales a la definición legal de familia, el catálogo de reglas que han otorgado derechos, así como sus límites y potencialidades. Posteriormente se muestran las reglas creadas por vía judicial y los principios aplicados. Como conclusiones se presentan conjeturas y retos para legisladores y jueces.

\section{LA DEMOCRACIA, CATÁLOGO DE REGLAS MÍNIMAS}

En la cátedra introductoria se enseña a los futuros abogados que el derecho es una herramienta neutra de las sociedades para lograr una convivencia pacífica. Sin embargo, en la práctica legal el derecho no solo está influido por la moral, sino que es fundamental para el ejercicio de la política; de hecho, se ubica como la bisagra entre la sociedad y la política (Habermas, 1998). Es así como la relación entre el régimen democrático, el derecho y la función de los jueces es básica para entender el papel de estos en la democracia.

Ahora bien, para entender el papel del juez es necesario tener en cuenta algunas posturas contemporáneas sobre los elementos mínimos de un régimen político para que pueda ser considerado como democracia. Desde Kelsen (1967), los teóricos del derecho han discutido si es posible un sistema jurídico fuera de un Estado democrático. En este sentido, se supone que el derecho no puede darse como sistema regulador de conductas sino en entornos aceptablemente democráticos. Entendiendo que existen posturas teóricas como la de Ferrajoli (2008), en la que el derecho solo puede concebirse dentro una democracia constitucional, resulta relevante exponer qué es una democracia constitucional para entrever el papel de la judicatura en ella. 
Para algunos abogados del siglo xx, la democracia empieza en el Ágora de Grecia. Se entiende que el régimen democrático es aquel en el cual todos participan de las decisiones fundamentales de la sociedad. Sin embargo, esta visión, además de ser ingenua, carece de evidencia empírica que la sostenga. Según Przeworski, «lo que tomaron del mundo antiguo no fue la 'democracia', sino la idea de una constitución mixta en la que la influencia del pueblo estuviera equilibrada y balanceada, ya no por la monarquía y la aristocracia sino al menos por la estructura de las instituciones representativas» (Przeworski, 2010: 39).

Así las cosas, la democracia es un sistema de gobierno en constante construcción y redefinición; el concepto de democracia y de autogobierno no fue importado de Grecia, sino que "[...] fue creciendo en forma gradual hasta llegar a ser una construcción nueva que tenía a la libertad como valor político supremo y, luego, afirmado que ese valor sólo se puede alcanzar si el pueblo es gobernado únicamente por las leyes determinadas por él mismo y a las cuales todos están sometidos por igual» (Przeworski, 2010: 43).

El uso indiscriminado de la palabra democracia para legitimar uno u otro tipo de gobierno desencantó a algunos de sus partidarios iniciales y poco a poco la hizo lucir despreciable, toda vez que reflejaba conexiones oscuras entre el poder y el dinero, leyes injustas e interminables conflictos. No obstante, la democracia no es nociva en sí misma. Es necesario delimitarla para hablar de una adecuada calidad de democracia.

Surge entonces la idea del gobierno a través de «equipos políticos seleccionados en elecciones periódicas» que tomarán decisiones de forma colectiva pero reflejando los intereses individuales de sus representados (Przeworski, 2010: 48). Para implementar dicho sistema, Przeworski propone cuatro límites a la democracia: a) la igualdad: «[...] cada uno de los participantes debe poder ejercer la misma influencia en la toma de decisiones colectiva $[\ldots] » ; \mathrm{b}$ ) la participación: «[...] deben tener alguna influencia efectiva en las decisiones colectivas[...]»; c) la representación: «[...] las decisiones colectivas deben ser implementadas por los elegidos para implementarlas[...]», y d) la libertad: «[...] el orden legal debe permitir la cooperación segura sin interferencias indebidas» (Przeworski, 2010: 49). Pero la aplicación exhaustiva de estos cuatro elementos implica disputas entre sí. En este orden, la construcción conceptual elaborada por Przeworski resulta particularmente útil para entender el papel del juez en la inclusión de derechos.

Sin embargo, las concepciones de democracia como un autogobierno complejo construida por Przerworski o la sencilla de la regla de la mayoría simple, expresada por el teorema de Rae (Przeworski, 2010: 81), resultan, en ocasiones, insuficientes para explicar el papel de los jueces, no en términos de dirimir los conflictos de los asociados sino en la toma de decisiones que per- 
miten la inclusión de derechos de ciudadanos excluidos por la mayoría en el catálogo de derechos democráticos. Se hace necesario entonces contar con una concepción de democracia que permita entender que las decisiones judiciales pueden ser vistas como herramientas de inclusión de derechos de minorías políticas históricamente excluidas, perseguidas, o invisibilizadas, como es el caso de la comunidad LGBTI.

Przeworski (2010) afirma que existen ordenamientos institucionales supermayoritarios o, incluso, directamente antimayoritarios en los que de manera ostensible se protege a las «minorías», entendiéndolas como grupos de ciudadanos que no tienen acceso a los derechos democráticos de los que gozan las mayorías. El ejemplo clásico es el de las mujeres, quienes en los últimos doscientos años han luchado por tener los mismos derechos que los hombres, y aunque constituyen mayoría en el número total de ciudadanos, siguen teniendo menor acceso a la educación o al trabajo que los hombres.

La democracia entonces se presenta como un autogobierno con límites fuertes en el ejercicio del poder, que busca, por un lado, garantías mínimas para los ciudadanos orientado por expectativas de imparcialidad e igualdad y, por otro, que las decisiones que tomen los servidores públicos sean legítimas en lo sustancial y en lo procedimental. En la democracia, a diferencia de otros ordenamientos políticos, se encuentran paz civil y libertad sin la amenaza de la fuerza (dictadura), índices de bienestar material y procedimientos institucionalizados como las elecciones competitivas (Przeworski, 2010: 85). Sin embargo, para el tema de este artículo resulta importante la definición de procedimientos institucionalizados a través de los cuales las minorías puedan acceder al catálogo de derechos.

\section{EL JUEZ CONSTITUCIONAL EN LAS DEMOCRACIAS, DEBATE VIEJO, ELEMENTOS NUEVOS}

El debate sobre la actividad del juez y su relación con la democracia no es meramente anglosajón. En la Teoría pura del derecho (1967), Kelsen entiende que el juez es mucho más que un simple árbitro, pues tiene una función jurídica creadora que se materializa cuando otorga el derecho mediante las sentencias judiciales. De hecho, Kelsen entiende que el juez constitucional tiene una función de legislador negativo cuando determina que alguna norma no se ubica dentro del marco constitucional y debe salir del ordenamiento jurídico. En síntesis, es posible afirmar que hay dos tipos de discusiones alrededor de la labor del juez: a) si deben o no crear derecho cuando promulgan sus fallos, y b) si crean o no reglas nuevas cuando los promulgan. Sobre el punto hay por lo menos dos posiciones que se pretenden resumir a continuación. 
Para ello resulta útil seguir a Posner (2011) y su crítica a la postura de John Glover Roberts cuando señaló que el juez, aun cuando sea del Tribunal Supremo, es como un árbitro de béisbol que se limita a cantar las bolas malas y los strikes (Posner, 2011: 95). Posner afirma que la analogía es desafortunada; sin embargo, la usa para mostrar cómo se puede tener una posición distinta a la expresada por Roberts.

Según este autor, hay tres árbitros de béisbol a los cuales se les pregunta cuál es la epistemología de las bolas malas y los strikes. El primer árbitro canta bolas o strikes cuando estos suceden, caso en el cual se estaría en presencia de alguien que considera que los jueces solo deciden sobre la norma aplicable al caso y la aplican (legalista); el segundo, cuando los ve, ya que es el juez quien decide qué y cuándo aplicar (el juez aplica el derecho ya legislado y en ocasiones lo crea); finalmente, el tercer árbitro explica que las bolas son buenas o malas cuando él lo decide, postura que da cuenta de que la labor del juez está más en crear el derecho que en descubrir la norma aplicable para cada caso. La discusión está abierta; sin embargo, es importante aclarar que al margen de ella para la lucha política de algunas minorías el papel del juez ha sido crucial en la defensa de sus derechos.

En otra orilla de la discusión se encuentra Sager (2007), para quien los jueces no son seguidores de instrucciones:

Los jueces establecen una relación de colaboración con las generaciones constituyentes que participaron en la elaboración del texto constitucional en el momento fundacional o en las sucesivas reformas. No son meros agentes. Esta colaboración tiene una estructura característica: al menos en relación con las cláusulas constitucionales garantes de libertad, la decisión del constituyente normalmente se expresa con un alto nivel de generalidad y de abstracción moral (Sager, 2007: 35).

Para Sager, el concretar los derechos conlleva una función creadora, pero a diferencia de otros considera que esta solo es posible dentro de un ámbito de colaboración entre los funcionarios del Estado.

Además de la colaboración entre poderes, Sager considera que el proceso judicial tiene virtudes que permiten que coadyuve a las demás instituciones del Estado para concretar los derechos de los ciudadanos consagrados en las cartas constitucionales que vale la pena resaltar (Sager, 2007: 91-93):

- La necesidad de un tercero para evaluar la correspondencia entre los derechos y los actos políticos.

- La justicia más allá de la política competitiva, sentido en el que los jueces hacen un aporte importante cuando concretan los derechos.

- La independencia judicial. 
- Los límites a los cuales se deben circunscribir los jueces, los cuales son barreras infranqueables que ningún funcionario puede traspasar en el ejercicio de sus funciones.

- La especialización del juez constitucional y de los límites de sus funciones.

Con la promulgación de la Constitución Política de 1991, en Colombia el debate sobre el papel de los jueces en la inclusión de derechos se tornó de tangencial a muy relevante. La Corte Constitucional colombiana y sus fallos han sido fundamentales para el acceso de los históricamente excluidos al catálogo de derechos. Solo a través de las sentencias de la Corte Constitucional los derechos de la comunidad LGBTI a reconocerse como ciudadanos, a la salud, al trabajo o a formar una familia han sido reconocidos e incorporados a la carta de derechos y han obligado al Estado colombiano a cumplir con las obligaciones de defensa y desarrollo de dichos derechos (Constitución Política de Colombia, 1991).

En síntesis, y parafraseando a Posner (2011), es posible afirmar que los jueces en general, y en especial quienes dirimen conflictos sobre los derechos de los ciudadanos, combinan casi inconscientemente las orientaciones legalistas legislativas de manera particular. Cuando enfrentan un caso específico responden a partir de la doctrina jurídica, los límites institucionales, sus propias preferencias en materia de políticas y sus consideraciones tanto estratégicas como relativas a la solución del caso en equidad, todas ellas mediadas a su vez por su propio temperamento, experiencia, ambición y otros factores personales (Posner, 2011: 102).

\section{LOS DERECHOS DE LAS MINORÍAS POLÍTICAS EN COLOMBIA: UN CATÁLOGO EN CONSTRUCCIÓN}

La lucha por los derechos de las minorías políticas no es un tema nuevo en las democracias modernas. La democracia colombiana no ha sido la excepción. En el siglo xx las mujeres tuvieron que luchar para abolir la potestad marital incluida en el derecho civil desde los inicios de la República (Ley 28 de 1932); posteriormente, en 1957 obtuvieron el derecho al voto, pero no fue hasta 1974 cuando alcanzaron la igualdad marital, a través del Decreto 2820.

El papel de los legisladores fue crucial para el reconocimiento de estos derechos, mientras que el de los jueces, durante los dos primeros siglos de República, fue tangencial y poco representativo. La lucha por la igualdad de derechos entre hombres y mujeres continúa incluso cuando registra progresos significativos. Derechos como los sexuales y reproductivos aún no se han con- 
sagrado de forma plena en favor de las mujeres - la interrupción del embarazo de manera voluntaria por la mujer en Colombia sigue siendo penalizada-

Con la promulgación de la Constitución de 1991 y la creación de la Corte Constitucional, el debate por los derechos ha ganado un escenario más para el logro de la inclusión. Este Tribunal ha jugado un papel básico en la inclusión de derechos y ha dinamizado el debate. Además, acudir al escenario constitucional ha sido una herramienta fundamental para los movimientos civiles que representan minorías políticas, para lograr el reconocimiento de derechos fundamentales y sociales. No obstante, esta vía ha sido sometida a diversas críticas, especialmente por parte de quienes integran los órganos legislativos, en tanto se tiene la percepción de que los jueces están suplantando el trabajo legislativo y tomando decisiones antidemocráticas. Este argumento es motivado por el hecho de que la elección de los jueces, a diferencia de los legisladores, no cumple con un procedimiento democrático (Waldron, 2005) colombiano en el que se exalta la importancia de la deliberación democrática para la construcción de un modelo de sociedad y el reconocimiento de derechos. Es por ello que la participación y decisión que se da en el seno de «la mayoría» se ve como la única herramienta plausible para garantizar el ejercicio democrático, partiendo de la idea de que la representación permite que las personas se sientan como iguales. No obstante, es necesario pensar en las dinámicas propias del ejercicio legislativo.

Por un lado, los intereses de las minorías deben encontrar cabida en la agenda legislativa. Esta es una primera barrera a la que se enfrentan ciertos grupos al momento de buscar el reconocimiento de derechos: no solo deben conseguir apoyo por parte de otros grupos (políticos y civiles) que apuesten por la defensa de sus intereses, sino que sus demandas están sujetas a una «cola». Por otro lado, la espera para poner a consideración del debate público demandas particulares tiene efectos determinados, tales como la violación de otros derechos supremos, amenazando a su vez la legitimidad del sistema democrático. Un ejemplo de ello es el recorrido que tuvo el reconocimiento del matrimonio por parte de parejas del mismo sexo que tuvo como escenario final la Corte Constitucional (López Medina, 2016; Quinche Ramírez y Peña Huertas, 2013), ante la negativa del legislador de pronunciarse sobre el tema (Parada Hernández y Gómez Álvarez, 2012; Sentiido, 2016).

4 Desde 1999 se han presentado alrededor de 10 proyectos de ley tendientes a regular los efectos patrimoniales de las uniones de parejas del mismo sexo (reconocidos mediante Sentencia de la Corte Constitucional C-075 de 2007), y el matrimonio entre personas del mismo sexo (reconocido mediante Sentencia de la Corte Constitucional SU-214 de 2016). 
Estas fallas en el sistema, que impiden un goce efectivo de derechos, han sido cubiertas acudiendo a órganos judiciales. Con ello se ha buscado que se reconozca, desde los principios constitucionales, la existencia de situaciones de hecho y su valor frente al sistema jurídico. De acuerdo con Gargarella (2008), y en concordancia con lo expuesto con Sager, se hace necesario repensar el papel de los órganos judiciales supremos como colaboradores del sistema democrático, y no como usurpadores de las labores legislativas. Esto en virtud de que la historia judicial nacional e internacional ha evidenciado que las conquistas de las minorías políticas se han dado en escenarios judiciales ante la imposibilidad de tramitar sus demandas en contextos en los cuales las mayorías reclaman la legitimidad para definir el curso de la vida social.

A continuación se examinan las reglas creadas por los jueces constitucionales en Colombia cuyo propósito ha sido la inclusión de los miembros de la comunidad LGBTI; posteriormente, a la luz de las teorías jurídicas se analizará el papel que han tenido en Colombia los jueces constitucionales en la inclusión de los derechos de esta comunidad.

Desde la segunda mitad del siglo xx la comunidad LGBTI colombiana ha luchado por el reconocimiento de sus derechos, pero es a partir de la promulgación de la Constitución Política de 1991 — una constitución garantista en su concepción y con retos muy grandes tanto para los legisladores como para los jueces constitucionales a los cuales se les otorgaba la guarda y garantía de que los derechos allí consagrados fueran efectivamente otorgados a los ciudadanos - cuando varios proyectos de ley han buscado vía Congreso ampliar el catálogo de derechos de la comunidad LGBTI, esto en virtud del principio de que:

El Estado tiene además la obligación de regular los derechos, completando su contenido y permitiendo su realización por medio de normas jurídicas. Aquí es necesario precisar que se trata de una obligación positiva, encaminada a lograr la efectivización del derecho por medio de normas y no a impedir su realización con regulaciones que hagan inane su contenido (Quinche Ramírez y Peña Huertas, 2013: 27).

Por otra parte, la Corte Constitucional ha resaltado que:

El legislador incurre en omisión legislativa relativa cuando ha regulado de manera insuficiente o incompleta un mandato constitucional; o cuando dicha insuficiencia de regulación (omisión de una condición o un ingrediente que de acuerdo con la Constitución, sería exigencia esencial para armonizar con ella) o incompleta reglamentación, conduce a la violación del derecho a la igualdad (Corte Constitucional. Sentencia C-209 de 2007). 
En materia de derechos de los ciudadanos que pertenecen a la comunidad LGBTI esta violación al derecho a la igualdad fue manifestada por la Corte Constitucional, instancia que en Sentencia C-577 de 2011 exhortó al Congreso para legislar a favor de los derechos de las parejas del mismo sexo, la cual dio lugar a los cinco proyectos de ley que buscaban la regulación del matrimonio de las parejas del mismo sexo, que no concluyeron el trámite legislativo.

Las propuestas fueron varias y muy disímiles, algunas conservadoras y otras de vanguardia como la que busca modificar el art. 113 del Código Civil que define el contrato solemne del matrimonio y cambiar la expresión «entre un hombre y una mujer» por la de «dos personas». Sin embargo, solo el último de estos proyectos llegó a primer debate en el Senado de la República antes del cumplimiento del plazo otorgado por la Corte Constitucional, el Proyecto de Ley 047 de 2012, que en principio propuso la creación de la institución de unión civily un régimen jurídico especial posteriormente modificado para solicitar el reconocimiento legal del matrimonio para las parejas del mismo sexo, lo cual transformó las disposiciones del Código Civil referidas al matrimonio y sus efectos civiles, de la Ley 250 de 1996 en el tema de vivienda familiar y de la Ley 495 de 1999 en el tema de patrimonio de familia (Peña Huertas y Parada Hernández, 2014: 89).

En el caso de los derechos de la comunidad LGBTI han confluido dos características. La primera es la incapacidad que ha tenido el Congreso de la República de abordar los temas de los derechos de la comunidad en materia de salud, seguridad social y trabajo, y en la oposición de la mayoría a regular los derechos sobre familia de dicha comunidad, lo cual, para algunos, constituye el incumplimiento por parte del Estado de sus obligaciones de regulación y que acarrea dos consecuencias directas: a) permite la violación de los derechos de esas personas, $\mathrm{y} \mathrm{b}$ ) perfecciona el incumplimiento [sic] de las obligaciones de regulación y garantía que jurídicamente el Estado tiene la obligación de atender (Quinche Ramírez y Peña Huertas, 2013: 89). La segunda característica de la regulación de los derechos de la comunidad LGBTI es que el reconocimiento y la regulación de sus derechos ha privilegiado la vía judicial en virtud de la consolidación de un sistema de reglas construido en los últimos veinte años por la Corte Constitucional, que permite la identificación de un corpus iuris alrededor de esos derechos.

Sin embargo, para la comunidad LGBTI el tratamiento jurisprudencial ha sido disímil a pesar de que la jurisprudencia constitucional ha determinado que los precedentes judiciales, especialmente los de la Corte Constitucional, tienen fuerza vinculante $y$, en el caso de los fallos de control abstracto de constitucionalidad y las sentencias condicionadas, en virtud de los efectos erga omnes de la decisión, ocupan el mismo lugar que la ley en el sistema de fuentes 
del derecho, debiendo ser acatados por la totalidad de los jueces y magistrados, las autoridades públicas y los particulares (Quinche Ramírez, 2014).

En este sentido, muchas de las sentencias de la Corte en el tema de derechos de las personas que pertenecen a la comunidad LGBTI tienen por sí mismas fuerza vinculante para todos los funcionarios del Estado, específicamente para quienes deben prestar un servicio cuya provisión sea obligación del Estado, como advierten algunos 5 .

A pesar del avance histórico de la Constitución de 1991 y de la Corte Constitucional en el reconocimiento de los derechos humanos, en la práctica la aplicación de esos derechos se encuentra con la continua resistencia de abogados, funcionarios y ciudadanos que se oponen a ellos por razones que van desde la ineficiencia hasta la indiferencia, mediados por las objeciones morales y los intereses personales. En el laberinto de las instituciones y las oficinas, de los incisos y los procedimientos, los derechos pueden perderse para siempre; por eso, con frecuencia, lograr el reconocimiento del derecho es apenas un primer paso en una larga marcha (Rodríguez et al., 2011).

A pesar de las limitaciones expuestas, son importantes los avances logrados en los últimos diez años en materia de reconocimiento de derechos por vía judicial para lograr una ciudadanía plena por parte de los miembros a la comunidad LGBTI. Los derechos que judicialmente se han logrado están contenidos en los siguientes fallos ${ }^{6}$ :

a) protección de los derechos patrimoniales de la pareja del mismo sexo (sentencia C- 075 de 2007) al examinar la Ley 959 de 2005.

b) Protección del derecho a la salud de la pareja del mismo sexo (sentencia C-811 de 2007).

c) Protección del derecho a la pensión ${ }^{7}$ de sobrevivientes de la pareja del mismo sexo (sentencia C- 075 de 2007 y C-336 de 2008).

d) Protección penal de los alimentos de la pareja homosexual (Sentencia C-798 de 2008) ${ }^{8}$.

e) Equiparación entre los derechos de las parejas heterosexuales y homosexuales (sentencia C-029 de 2009).

5 Ver Quinche Ramírez y Peña Huertas (2013).

6 Para ver en profundidad las reglas creadas por la Corte Constitucional ver Quinche Ramírez y Peña Huertas (2013).

7 Derechos de seguridad social.

8 En esta sentencia, la Corte, de manera tácita, determina que es posible que las parejas del mismo sexo conformen familia debido a que se amplió el concepto de familia al penalizar a la pareja del mismo sexo por inasistencia alimentaria, delito contra la familia, título VI del Código Penal. 
f) Protección del matrimonio y la familia conformada por parejas del mismo sexo (sentencia C-577 de 2011). La Corte se abstuvo de declarar la exequibilidad condicionada9 del art. 113 del Código Civil, que define el contrato solemne del matrimonio como la unión entre un hombre y una mujer, tal y como venía haciéndolo con las normas demandadas que establecían discriminación por género. En sentido contrario, declaró la exequibilidad del enunciado en el numeral primero de la parte resolutiva del fallo y aunque la Corte reconoció que resulta discriminatorio el hecho de que no exista una forma alternativa que cobije las uniones maritales de esta comunidad, esto no soluciona la situación. Luego de que por una amplia mayoría fuera derrotado el proyecto de ley 047 de 2012, que regulaba la institución del matrimonio entre personas del mismo sexo, algunos jueces y notarios han realizado matrimonios, uniones solemnes y otro tipo de celebraciones para legalizar las uniones maritales de hecho de las parejas del mismo sexo. De acuerdo con la Superintendencia de Notariado y Registro, en 2013 se realizaron en Colombia 152 uniones solemnes de parejas del mismo sexo y 164 en 2014, ante notarios. Sin embargo, La Unión Colegiada de Notariado a través de su presidente afirmó que en 2014 se realizaron cerca de 2500 contratos de este tipo ${ }^{10}$.

g) Prohibición de excluir a las parejas del mismo sexo de los procesos de adopción por considerarse un límite al derecho de los niños a tener una familia y no ser separados de ella (Sentencia C-683 de 2015).

h) Protección a hijos que tienen una relación filial con una pareja del mismo sexo: deben ser registrados como tal. Además, se ordenó modificar los formularios de registro civil de nacimiento para que en el futuro cobijen a las familias diversas (Sentencia SU-696 de 2015).

i) Protección del derecho a suceder de la pareja del mismo sexo (sentencia C-238 de 2012).

j) Protección a la familia adoptiva homoparental: la Corte, mediante sentencia T-276 de 2012, protegió el derecho de los menores a ser adoptados con la salvedad de que la condición sexual de los potenciales padres no puede ser impedimento para que la medida de protección se otorgue. De igual manera, en sentencia SU-617 de 2014, la Corte protege el derecho de una menor a ser adoptada y ordena seguir el trámite administrativo ante el ICBF.

k) Reconocimiento del derecho de parejas del mismo sexo a contraer matrimonio. La Corte, mediante sentencia de unificación SU-214 de 2016,

9 Solicitada en la demanda.

10 El Tiempo, 6 de enero 2015, pág. 4. 
indica que la forma en la que la Constitución describe el matrimonio (vínculo entre un hombre y una mujer), no excluye la posibilidad de que el vínculo se celebre entre mujeres o entre hombres.

Lograr que los derechos de la comunidad LGBTI sean reconocidos por las mayorías en el Congreso, en un país mayoritariamente católico y conservador como Colombia, ha sido una lucha titánica pero infructuosa. Surgió así un cambio de estrategia derivado del ejemplo de otras comunidades que lograron reconocimiento a través del litigio constitucional, el cual ha permitido a la comunidad LGBTI enfilar sus argumentos hacia los jueces constitucionales para lograr a través de fallos judiciales lo que vía Congreso no ha sido posible. Los resultados que ha arrojado esta estrategia han sido positivos: en la década de los años noventa se logró el respeto a la libertad sexual, en la primera década del siglo XxI el respeto de los derechos de las parejas del mismo sexo así como el reconocimiento de sus derechos patrimoniales y de seguridad social. Sin embargo, el papel del legislador no se ha agotado y en este sentido es necesario buscar el reconocimiento vía legislativa.

\section{DESARROLLO DE LA JURISPRUDENCIA CONSTITUCIONAL DE DEFINICIÓN DE FAMILIA}

En Colombia, a partir de la entrada en vigencia de la Constitución de 1991, el desarrollo de reglas por parte de los jueces ha sido muy importante. De acuerdo con López, en el país se han dado profundas discusiones sobre el papel de la jurisprudencia y la judicatura que se han profundizado con la promulgación de la Carta Política de 1991 (López, 2006).

El art. 42 de la Constitución indica que

la familia es el núcleo fundamental de la sociedad. Se constituye por vínculos naturales o jurídicos, por la decisión libre de un hombre y una mujer de contraer matrimonio o por la voluntad responsable de conformarla. El Estado y la sociedad garantizan la protección integral de la familia. La ley podrá determinar el patrimonio familiar inalienable e inembargable (Constitución Política de Colombia, 1991).

Muchas políticas públicas sobre educación, salud, seguridad social, vivienda, etc., se hacen teniendo en cuenta la familia; en este sentido, es relevante para los miembros de las comunidades LGBTI que se les reconozca el derecho a formar una familia.

La Corte Constitucional interpretó ampliamente la definición de familia consagrada en el art. 42 de la Constitución; es el caso de las sentencias C-521 
y C-811 de 2007. La primera considera que el impedimento que tiene la pareja del mismo sexo de vincularse al sistema de seguridad social en salud en el régimen contributivo constituye una vulneración de su derecho a la dignidad humana, al libre desarrollo de la personalidad — por cuenta de la autodeterminación sexual-, así como una transgresión al mandato de no discriminación por razón de la orientación sexual del individuo si se tiene en cuenta que es la propia condición homosexual la que, aunada a la decisión de vivir en pareja, determina la exclusión del privilegio legal, por lo que la norma resulta lesiva del principio de igualdad constitucional. De esta manera, la Corte Constitucional construyó un camino largo en la concepción de familia que incluyera a aquellas que se conforman por la voluntad de dos personas del mismo sexo, de acuerdo con lo previsto en la Constitución.

En el mismo sentido, en la Sentencia C-811 de 2007, la Corte Constitucional declaró la exequibilidad condicionada del art. 163 de la Ley 100 de 1993, en el entendido de que la cobertura del sistema de seguridad social en salud del régimen contributivo también admite la de las parejas del mismo sexo. La diversidad de situaciones en que los vínculos de esta clase surgen en las sociedades actuales lleva a desechar la idea de que es la heterosexualidad la que está en la base de la protección constitucional de la familia. En el cuerpo de esta sentencia se agrega que a partir de una nueva, más realista y plural concepción de la familia, es posible concebir un universo diverso de formas de relación entre personas que merecen protección constitucional, como el núcleo afectivo que se establece entre la madre cabeza de familia y su(s) hijo(s), entre los abuelos y los nietos, de los que, por múltiples motivos, deben hacerse cargo, de los tíos y tías que, por diversas circunstancias.

La Corte Constitucional en sentencia C-577 de 2011 advierte del déficit de protección en lo que entraña los derechos de ciudadanos LGBTI. En la legislación el silencio del legislador posiblemente es una de las causas de que haya un activismo judicial muy dinámico en los últimos diez años sobre el tema de derechos de esta comunidad. Sin embargo, este activismo y los pronunciamientos de la Corte no han sido suficientes para que los ciudadanos de la comunidad LGBTI gocen plenamente de sus derechos.

A pesar de que la Corte reitera que sus disposiciones constituyen derecho y están encaminadas a la creación de reglas jurídicas que deben ser aplicadas por autoridades administrativas y judiciales, para muchos operadores del sistema jurídico la norma expedida por la Corte no tiene el mismo estatus social que aquella que es producto de un debate público y que posteriormente es plasmada en una ley de la República (Peña Huertas y Parada Hernández, 2014). 


\section{DOS EJEMPLOS DE INCLUSIÓN JUDICIAL Y DERECHOS DE FAMILIA HOMOPARENTAL}

La lucha por la inclusión del derecho de los ciudadanos de la comunidad LGBTI por conformar una familia con las mismas condiciones que gozan los ciudadanos heterosexuales ha sido mucho más difícil en comparación con el reconocimiento de otros derechos; sin embargo, dos sentencias de la Corte Constitucional son las bases para un desarrollo legal y jurisprudencial en este sentido. Ambas hacen referencia al derecho de menores de edad a tener una familia mediante la medida de protección de la adopción, sin importar la inclinación sexual de los padres o madres aportantes.

A diferencia de las anteriores ocasiones, esta sentencia es sobre un caso de tutela (amparo) en la que, sin proponérselo explícitamente, la Corte evidenció que en Colombia la familia adoptiva homoparental se reconoce y tiene derechos. En la Sentencia T-276 de 2012, además de solucionar el caso, la Corte estableció que es necesario que el derecho de los niños a tener una familia es superior y que la decisión de que sean adoptados no puede pasar por la inclinación sexual de los padres adoptantes.

Por otra parte, en 2014, la Sentencia SU-617 es uno de los casos más conocidos por el país sobre el derecho de una niña a ser adoptada por la pareja de su madre biológica. Así, la Corte Constitucional concedió el amparo de los derechos fundamentales de la menor Lakmé y de las peticionarias Turandot y Fedora a la autonomía familiar y a tener una familia y ordenó a la Defensoría de Familia n. ${ }^{\circ} 2$ de Rionegro revocar la declaratoria de improcedencia de la solicitud de adopción - fundada en la homosexualidad de la pareja conformada por Turandot y Fedora- y que, en su lugar, se continúe con el trámite administrativo correspondiente sin que tal consideración pueda ser invocada para excluir la adopción de Lakmé y sin perjuicio de que las autoridades exijan el cumplimiento de los demás requisitos legales, con estricta sujeción a los perentorios términos previstos para este trámite (Sentencia SU-617, 2014).

Las reglas establecidas por la Corte en estos dos casos mencionados fueron acogidas en un último fallo (C-683 de 2015) mediante el cual se prohibió excluir a las parejas del mismo sexo de los procesos de adopción, no solo continuando con el cuestionamiento del género como una categoría sospechosa, sino porque de no permitir que pareja del mismo sexo puedan adoptar, se vulneraría el derecho de los niños a tener una familia y no ser separados de ella.

Después de haber obtenido por vía judicial el reconocimiento de derechos sociales y civiles por parte de la comunidad LGBTI, aún hay mucho por recorrer; las sentencias han sido disímiles en su tratamiento y, además, pareciera que estas sentencias exigen que para que las parejas del mismo sexo accedan a la salud u obtengan una pensión de sobreviviente deban hacer una 
declaración conjunta de los compañeros permanentes para acreditar la unión marital de hecho, cosa que es lógica en asuntos de cobertura de salud. Sin embargo, este requisito es problemático para la obtención de la pensión de sobreviviente, pues muchas veces uno de los compañeros permanentes muere antes de hacer la acreditación de la unión marital ante notario, haciendo materialmente imposible la declaración conjunta, como lo exige la sentencia C-811 de 2007. Y es que si bien la sentencia mejora la posición de las parejas del mismo sexo, les impone obligaciones que las parejas heterosexuales no tienen: la comprobación de su calidad y la vocación de permanencia deben regularse por el mismo mecanismo establecido en la sentencia C-521 del 2007, esto es, declaración ante notario en la que conste que la pareja convive efectivamente y que dicha convivencia tiene vocación de permanencia, independientemente de su tiempo de duración (Rodríguez et al., 2011).

\section{ALGUNAS CONJETURAS A MANERA DE CONCLUSIONES}

Existen muchos momentos en la historia de las democracias modernas en los que el papel de los jueces ha sido crucial para la defensa de los derechos de las minorías políticas. En este sentido, los jueces tienen un papel fundamental que no se contradice con la división o equilibrio de poderes; por el contrario, esta función se hace fundamental para el ejercicio pleno de los derechos.

Según Sapiro (1999), la jurisprudencia resuelve un problema jurídico específico, pero deja abierta la puerta a nuevas cuestiones, crea nuevas incertidumbres que deben ser resueltas de manera concreta, por lo que el papel del juez en las democracias será básico para el desarrollo pleno de los derechos de los ciudadanos.

El caso de los derechos de la comunidad LGBTI es un ejemplo interesante para mostrar el papel de los jueces en las democracias en desarrollo como la colombiana. En el proceso para lograr el reconocimiento del matrimonio entre personas del mismo sexo, el derecho a conformar una familia, así como los demás derechos colaterales que surgen de estas decisiones, el papel de los tribunales es de gran importancia por varias razones: a) porque los tribunales no tienen la presión de las mayorías para tomar las decisiones y estas ejercen una presión sobre las sociedades y los parlamentos para que se reajuste el sistema jurídico favoreciendo a las minorías discriminadas, como es el caso de la población LGBTI, y b) si bien el escenario legislativo debe apropiarse de los debates de inclusión de los derechos - porque es allí donde confluyen diversas voces y fuerzas que construyen nuevas formas de vivir la ciudadanía, con aspiraciones de convertir en norma jurídica la protección integral de la diferencia, dejando a un lado la distinción entre ciudadanos de primera y segunda 
categoría - los jueces pueden marcar pautas estratégicas para la protección de dichos derechos (Peña Huertas y Parada Hernández, 2014) porque llevar este tipo de discusiones a los tribunales abre el debate público sobre los derechos de los ciudadanos y las acciones con las que estos cuentan para hacerlos valer en democracias modernas donde las constituciones se han convertido en herramientas normativas de inclusión en la democracia.

\section{BIBLIOGRAFÍA}

Calle, A. y García, C. (2012). Evolución del concepto legal de familia y sus implicaciones en el reconocimiento de familias homoparentales en sus diversas formas. Ponencia presentada en el II Concurso Nacional de Semilleros de Investigación. Bogotá: Universidad del Rosario.

Ceballos Ruíz, P. A. y Ríos Quintero, J. V. (2012). El reconocimiento de derechos a las parejas del mismo sexo: el camino hacia un concepto de familia pluralista. Estudios Socio Jurídicos, 12 (2), 207-239.

Ferrajoli, L. (2008). Democracia y garantismo. Madrid: Trotta.

Gargarella, R. (2008). Teoría y crítica del derecho constitucional. Buenos Aires: Abeledo Perrot.

Habermas, J. (1998). Factividad y validez: sobre el derecho y el Estado democrático en Términos de teoría del discurso. Madrid: Trotta.

Kelsen, H. (1967). La teoria pura del Derecho. Mexico: Porrúa.

Lee, T. T. y Hicks, G. (2011). An analysis of factors affecting attitudes toward same - sex marriage: do the media matter? Jorunal of Homosexuality, 1391-1408.

López, D. (2006). La teoría impura del Derecho (2a ed.). Bogotá: Temis.

López Medina, D. (2016). Cómo se construyen los derechos. Narrativas jurisprudenciales sobre orientación sexual. Bogotá: Legis.

Moskowitz, D., Rieger, G. y Roloff, M. (2010). Heterosexual attitudes toward same-sex marriage. Jorunal of Homosexuality, 57 (2), 325-336.

Parada Hernández, M. M. y Gómez Álvarez, J. C. (2012). Inclusióm democrática: los nuevos retos del Legislativo en materia de derechos de las familias LGBTI en Colombia. En M. L. Torres y P. M. Iregui. Reflexiones sobre la libertad de expresión en el contexto de la democracia (pp. 1-32). Bogotá: Universidad del Rosario.

Peña Huertas, R. P. y Parada Hernández, M. M. (2014). Tensión entre la democracia inclusiva y la mayoría: el matrimonio igualitario en el Congreso Colombiano. Revista de Derecho, 42, 65-95.

Posner, R. A. (2011). Cómo deciden los jueces. Madrid: Marcial Pons.

Proyecto de Ley 047 (Congreso de la Repúblical. República de Colombia 2012).

Przeworski, A. (2010). Qué esperar de la democracia. límites y posibilidades del autogobierno. Buenos Aires: Siglo Veintiuno.

Quinche Ramírez, M. F. (2014). El precedente judicial y sus reglas. Bogotá: Legis. 
- y Peña Huertas, R. P. (2013). El derecho judicial de la población LGBTI y de la familia diversa. Bogotá: Universidad del Rosario, Legis.

Rodríguez, C., Albarracín, M., Soto, C., Camacho, A. y Méndez, M. A. (2011). ¿Sentencias de papel? Efectos y obstáculos de los fallos sobre los derechos de las parejas del mismo sexo en Colombia. Bogotá: Ediciones Uniandes.

Sager, L. (2007). Juez y democracia. Una teoría de la práctica constitucional norteamericana. Madrid: Marcial Pons.

Sapiro, I. (1996). Democracy's Place. Ithaca: Cornell University Press.

Sentiido (2016). Matrimonio igualitario en Colombia, paso a paso. Recuperado el 4 de Mayo de 2016, de Sentiido: http://sentiido.com/linea-del-tiempo-matrimonio/.

Waldron, J. (2005). Derecho y desacuerdos. Madrid: Marcial Pons.

\section{LEGISLACIÓN Y JURISPRUDENCIA}

Colombia. Constitución Política (1991).

Colombia. Congreso de la República (1993). Ley 100.

Colombia. Congreso de la República (1996). Ley 250.

Colombia. Congreso de la República (1999). Ley 495.

Colombia. Corte Constitucional (2007). Sentencia C - 075.

Colombia. Corte Constitucional (2007). Sentencia C - 209.

Colombia. Corte Constitucional (2007). Sentencia C - 251.

Colombia. Corte Constitucional (2007). Sentencia C - 521.

Colombia. Corte Constitucional (2007). Sentencia C - 577.

Colombia. Corte Constitucional (2007). Sentencia C - 811.

Colombia. Corte Constitucional (2008). Sentencia C - 336.

Colombia. Corte Constitucional (2008). Sentencia C - 798.

Colombia. Corte Constitucional (2014). Sentencia SU - 617, Expediente T-2597.191.

Colombia. Corte Constitucional (2015). Sentencia C - 683.

Colombia. Corte Constitucional (2016). Sentencia C - 214. 